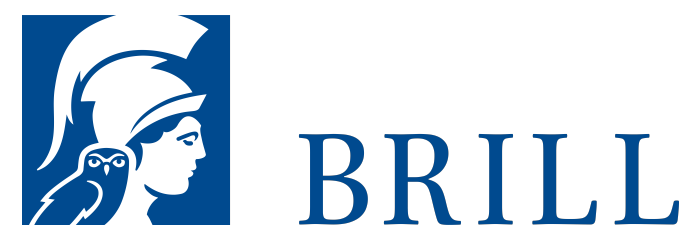

\title{
Speichern und Übertragen
}

Mediale Ordnungen des akustischen Diskurses. 1900-1945

Author: Kathrin Dreckmann

Ein grundlegender und umfassender Beitrag zur

Medienkulturgeschichte des akustischen Speicherns und Übertragens: Die Studie zeichnet den Prozess nach, durch den die »Volksgemeinschaft « sich in den Körper einschreibt. In den vergangenen 15 Jahren hat die Medienkulturwissenschaft sich verstärkt mit der kulturellen Bedeutung von medientechnisch gespeicherten Klängen, Tönen, Geräuschen und Stimmen beschäftigt. Kathrin Dreckmann leistet die systematische Aufarbeitung einer akustischen Medienspeicherkultur. Angefangen bei den ersten grammophonischen Produktionen bis hin zu NSRundfunkpolitik, die auf die medien-technischen Dispositionen des Weimarer Rundfunks aufbaute, werden die Spezifika des akustischen Übertragungs- und Speicherdispositivs herausgearbeitet. Die Arbeit fragt nach Kontinuitäten der medialen Erfahrung bis in die Nachkriegszeit hinein.

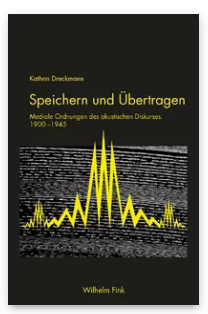

Pages: 357

Seiten, $12 \mathrm{~s} / \mathrm{w}$

Abb.

Language:

German

Publisher: Brill |

Fink

E-Book (PDF)

Released online:

13 Dec 2017

ISBN: $978-3^{-}$

$8467-6212-7$

List price

Paperback

Publication date:

o1 Dec 2017

ISBN: 978-3-

7705-6212-1

List price 
Kathrin Dreckmann studierte Germanistik, Geschichte und Philosophie an der Heinrich-Heine-Universität Düsseldorf (HHU). Seit 2009 ist sie wissenschaftliche Mitarbeiterin am Institut für Medien- und Kulturwissenschaft der HHU. Ihre DIssertation mit dem Titel „Übertragen und Speichern. Mediale Ordnungen des akustischen Diskurses 1900-1945" hat sie im Jahre 2015 mit der Gesamtnote „Summa Cum Laude“ abgeschlossen.

For more information see brill.com

Order information: Order online at brill.com +44 330333 0049 | customerservices@brill.com Submission information: brill.com/authors

Titles published by Brill | Fink, Brill | mentis or Brill | Schöningh: +49(o)71 5413279216 | brill@brocom.de 